\title{
Albanian Teachers' Perceptions about Difficulties in Teaching and Learning Grammar of EFL
}

\author{
Lindita Kaçani \\ Suela Mangelli
}

"Fan S. Noli" University, Korca, Albania

Email: Ikacani@yahoo.com

Email: suelamangelli@gmail.com

Doi:10.5901/jesr.2013.v4n3p149

\begin{abstract}
The English Language School Program in Albania aims at enabling learners to use the language effectively in both written and oral communication. Since effective communication is greatly dependent on grammatical accuracy, English language teachers have the responsibility to help learners develop grammatical competency apart from communicative competency. The aim of this study is to investigate teachers' perceptions concerning the difficulties faced by school teachers and learners in teaching and learning EFL grammar for communicative purpose in Albania. Such awareness may help the teacher in choosing the right teaching option that would pose fewer difficulties and problems to their learners and therefore, enhance students' learning of English grammar. This paper gives the data analysis of a questionnaire given to 58 teachers teaching English at different levels aiming to find out whether teachers' perceptions regarding grammar teaching and learning varied according to the level they taught English. Mean scores were used to interpret the data.
\end{abstract}

Keywords: teachers' perceptions, EFL grammar teaching, EFL grammar learning, difficulties

\section{Introduction}

Since 1993, according to the Albanian Ministry of Science and Education, curricula and teaching materials of foreign languages have been in the process of improvement based on the European standards. Thus, actually, the English Language School Program in Albania aims at equipping students with basic language skills and knowledge of the English language so as to enable them to use the language effectively in both written and oral communication.

But effective communication is greatly dependent on grammatical accuracy, as grammar competence is part of communicative competence (Celce-Murcia, 1991). Hence, English language teachers have the responsibility to help learners develop grammatical competency apart from communicative competency and proficiency if the aim of English Language Program is to be achieved. Being aware of teachers' and learners' difficulties in teaching and learning English grammar for communicative purpose may help the teacher in choosing the right teaching option that would pose fewer difficulties and problems to their learners and therefore, enhance students' learning of English grammar.

The aim of this study is to investigate teachers' perceptions concerning the difficulties faced by school teachers and learners in teaching and learning EFL in Albania. The data are also compared to see whether their perceptions of difficulties vary according to the level teachers taught EFL.

This study is limited to EFL teachers teaching English in two regions of Albania (Korça and Shkodra) and the use of the questionnaire as the research instrument.

\section{Literature review}

\subsection{Attitudes towards grammar instruction}

A review of FL teaching history shows that the role of grammar and the approach to grammar teaching have been controversial (Larsen-Freeman, 2000; Richards \& Rodgers, 2001; Richards \& Renandya, 2002). Under the influence of the theoretical and empirical developments in language acquisition and other sciences (such as linguistics, psychology and sociolinguistics) as well, the differing views and conceptions of grammar and its teaching and learning has led to different views and approaches to teaching grammar. The traditional approach, focus on forms, emphasized the role of 
grammar in FLL (grammar-translation, audio-lingual, oral and situational, silent way, total physical response, presentation-practice-production); classroom activities focused on learning grammatical rules and analyzing language forms with little focus on language functions (Richards \& Rodgers, 2001). The other approach, focus on meaning, diminished the role of grammar in foreign language learning; it developed syllabi based on functional use of language (communicative method, notional-functional, content-based, task-based), where the activities focused on conveying meaning in a communicative context but paying little attention to the language forms used to convey it. But foreign language acquisition research has recently suggested that some conscious attention to grammatical forms is necessary to develop high levels of accuracy in the target language. As a result, there is recently an agreement among researchers, educators and teachers on the necessity to teach grammar. Focus on form (focus on forms and meaning, grammar and communication) approach intends to draw learners' attention to linguistic forms in the context of meaningful communication.

In this vain, the present issue is how to teach grammar effectively (Richards \& Renandya, 2002, p. 145; Ellis et al. 2009). Different frameworks for grammar instruction have been proposed incorporating a focus on form into meaningful communication (Larsen-Freeman, 2000; Nassaji \& Fotos, 2011). The challenge before a language teacher is to choose the right approach or to integrate the concepts of different approaches to suit their own learners and classroom environment.

\subsection{What makes learning and teaching FL grammar difficult?}

This issue has been of considerable interest to researchers and teachers. Referring to some of them, grammatical difficulty is considered in relation to:

- Comprehension and production. DeKeyser and Sokalski (1996) argue that some grammar structures are easy to comprehend but difficult to produce, some others are easy to produce, but difficult to comprehend. For Albanian speakers learning English, comparative and superlative forms of one-syllable adjectives exemplify the former case, while the use of some prepositions exemplifies the latter.

- Complexity of the grammatical feature. Some researchers (DeKeyser, 1995; Ellis, 1997; Ellis et al. 2009; Nassaji \& Fotos, 2011; Spada \& Lightbown, 2008) consider some linguistic forms (such as English articles) structurally simple but functionally very complex as they perform a number of different functions (relating to type of the noun they determine, the situational context and the discourse context). In such cases, the complex feature will require a complex explanation, using even technical metalanguage (as generic/specific reference or countable/uncountable nouns).

- Linguistic form (the accurate use of a grammatical feature), semantic meaning (understanding the message encoded by a lexical item or a lexico-grammatical feature) and pragmatic use (using a lexico-grammatical feature appropriately in a context) (Celce-Murcia \& Larsen-Freeman, 1999; Larsen-Freeman, 2003). According to Larsen-Freeman, a grammar feature can be easy relating to one aspect, but difficult to another. For example, the form of the English passive is easy to learn, but its use is more difficult. Thus, it is challenging for FL learners to learn to use grammar structures accurately, meaningfully, and appropriately in a certain communicative context.

- Implicit/explicit knowledge: Ellis (2006) distinguishes two senses of grammatical learning difficulty: (1) "the difficulty learners have in understanding a grammatical feature," and (2) "the difficulty [learners] have in internalizing a grammatical feature so that they are able to use it accurately in communication" (p. 88). Ellis argues that a grammatical feature may be difficult to learn as explicit knowledge, but easy as implicit knowledge, and vice versa (Ellis et al. 2009, p. 164).

Grammatical difficulty has also been discussed in FL acquisition with reference to other factors, including: complexity of rules, salience of a grammar form in the input, communicative force of a grammar form, learner's developmental stage, L1 transfer, individual differences in language aptitude (Nassaji \& Fotos, 2011; Burgess \& Etherington, 2002).

\subsection{Studies on teachers' perceptions regarding teachers' and learners' difficulties in grammar instruction and learning}

Educational research has recently supported the assertion that teachers' classroom practices are determined by their personal pedagogical belief systems (stores of their beliefs, knowledge, theories, assumptions and attitudes) (Borg, 1998). The inconclusive debate about the best way to teach grammar may be feeding the development of teachers' 
personal pedagogical belief systems, and therefore the development of different grammar and language teaching practices. For this reason, it becomes necessary to investigate FL teachers' pedagogical belief systems.

There have been a number of studies on teachers' belief system about grammar and grammar teaching and learning. Al-Mekhlafi and Nagaratnam (2011), Burgess and Etherington (2002), Baleghizadeh and Farshchi (2009) have also studied teachers' perceptions regarding teachers' and learners' difficulties in EFL grammar instruction and learning.

The findings from these studies indicate that in teachers' perceptions, both teachers and learners faced difficulties regarding EFL grammar instruction and learning. Speaking in more details regarding these three studies:

- the learners favored explicit grammar teaching because of their expectations and feelings of insecurity;

- they had difficulty in internalizing grammar rules though they valued positively both the use; of formal instruction and natural exposure to language through authentic materials, their learners;

- $\quad$ their learners found grammatical terminology useful, but not in Burgess and Etherington's survey (2002); its use did not present a particular difficulty for learners;

- all the teachers believed that grammatical errors should be corrected, even when communicative goals are attained. Al-Mekhlafi and Nagaratnam (2011), Burgess and Etherington (2002) also concluded that the responded teachers experienced more difficulty in correcting their learners' spoken rather than written communication. Unlike them, Baleghizadeh and Farshchi (2009) found that most of the teachers did not seem to have difficulty correcting learners' errors of grammar within communicative context;

- though teachers valued the use of authentic texts, their use for presenting and practicing grammar was seen as posing problems to teachers and students because of the variety of structures, culture, vocabulary, formfunction matches, amount of time needed for using them and producing suitable tasks from them. Unlike AlMekhlafi and Nagaratnam (2011), Baleghizadeh and Farshchi (2009), teachers in Burgess and Etherington's survey (2002) did not believe that grammar in authentic texts was too difficult for their learners; the existence of the specialized vocabulary seemed to be a problem for them;

- all teachers valued the use of practice and problem-solving tasks in learning grammar and improving grammar accuracy. Al-Mekhlafi and Nagaratnam (2011) concluded that both written and communicative activities posed difficulties to learners in learning grammar, where writing activities were more challenging than spoken ones.

There has been little investigation of the difficulties faced by Albanian teachers and learners of EFL. Identifying such difficulties and being consciously aware of them would help teachers find ways to overcome them and provide effective grammar instruction.

\section{Research methodology}

\subsection{Participants}

A total of 58 in-service Albanian teachers of English as a foreign language are the subjects of this study (more than the minimum number required for making useful statistical analyses (Cohen \& Manion, 1994, p. 77). Teachers teaching English at three different levels were purposively selected aiming to find out whether teachers' perceptions regarding grammar teaching and learning varied according to the level they taught English: 20 teachers teaching English at grades 5-9, 20 at grades 10-12 and 18 at university of Korça and Shkodra.

\subsection{Instrument}

The instrument used in the study was the questionnaire adapted from Burgess and Etherington (2002). The questionnaire consisted of 20 statements which concentrated on these pedagogical issues: 1) explicit grammar teaching (statements $3,4,5,13)$, the transfer of declarative knowledge into procedural knowledge $(1,17,18)$, the use of grammatical terminology $(14,19)$, error correction $(15,16)$, problem-solving activities $(2,20)$, the use of authentic texts for grammar teaching and learning $(6,7,8,9,10,11,12)$, the use of spoken and written communicative activities (17, 18).

Teachers were asked to respond to each statement on a five-point Likert-type attitude scale using (1) SD = strongly disagree, (2) D = disagree, (3) $\mathrm{N}=$ neither agree nor disagree, (4) A = agree, or (5) SA = strongly agree.

They answered the questionnaire in their own time and returned it anonymously. 


\section{Findings and discussion}

Analyzing the teachers' answers to the all statements (as shown in table 1) regarding to difficulties faced by teachers and learners with grammar instruction, it is provided the average result of 3.16 (closer to the positive end than to the negative) suggesting that in the responded teachers' perceptions, there are difficulties faced by teachers and learners regarding EFL grammar instruction.

Table 1. Teachers' perceptions of difficulties with EFL grammar

\begin{tabular}{|c|c|c|c|c|c|c|c|c|c|c|c|c|c|c|c|c|c|c|c|}
\hline \multirow{2}{*}{$\begin{array}{l}\text { State } \\
\text { ment }\end{array}$} & \multicolumn{6}{|c|}{ Grades: 5-9 (20 teachers) } & \multicolumn{6}{|c|}{ Grades: 10-12 (20 teachers) } & \multicolumn{6}{|c|}{ University level (18 teachers) } & \multirow{2}{*}{$\begin{array}{l}\text { Total } \\
\text { mean }\end{array}$} \\
\hline & SD & $\mathrm{D}$ & NA & $\mathrm{A}$ & SA & Mean & SD & $\mathrm{D}$ & NA & $\mathrm{A}$ & SA & Mean & SD & $\mathrm{D}$ & NA & $\mathrm{A}$ & SA & Mean & \\
\hline 1 & 0 & 10 & 6 & 4 & 0 & 2.7 & & 6 & 6 & 6 & 2 & 3.2 & 2 & 2 & 4 & 8 & 2 & 3.33 & 3.07 \\
\hline 2 & & 4 & 4 & 10 & 2 & 3.5 & & & 7 & & & 3.65 & - & & 8 & & 1 & & 3.51 \\
\hline 3 & - & - & - & 14 & 6 & 4.3 & 2 & 2 & 2 & 8 & & 3.7 & - & 2 & 1 & 8 & 7 & 4.11 & 4.03 \\
\hline 4 & 1 & 9 & 5 & 5 & - & 2.7 & - & & 6 & 6 & 6 & 3.8 & - & & - & 10 & 2 & 3.44 & 3.31 \\
\hline 5 & & - & 2 & 18 & - & 3.9 & 3 & & 1 & 10 & & 2.9 & - & & 10 & & 2 & & 3.34 \\
\hline 6 & 2 & 7 & 8 & 2 & 1 & 2.65 & 2 & & 4 & 8 & - & 2.9 & 2 & 2 & 4 & 10 & - & 3.22 & 2.92 \\
\hline 7 & - & 9 & 5 & 3 & 3 & & 2 & & 8 & & 2 & 2 & - & & 3 & 6 & 6 & & 3.24 \\
\hline 8 & 2 & 11 & 2 & 3 & 2 & 2. & 2 & & 5 & & & 3.25 & 4 & & & & & 2.39 & 2.75 \\
\hline 9 & - & 12 & 5 & - & 3 & & - & $\xi$ & 2 & $\varepsilon$ & 2 & & - & . & 6 & 8 & 4 & 3.89 & 3.26 \\
\hline 10 & - & 5 & 8 & 5 & 2 & & - & & 3 & 6 & & & - & 2 & 2 & 8 & 6 & 4 & 3.56 \\
\hline 11 & - & 11 & 6 & 2 & 1 & 2.65 & 6 & & 4 & & & 2. & 3 & 10 & & & - & 2.22 & 2.35 \\
\hline 12 & 2 & 12 & 6 & - & - & 2. & 2 & $\varepsilon$ & 5 & 2 & & 2 & 2 & 4 & 6 & 6 & - & 2.89 & 2.6 \\
\hline 13 & - & 2 & 2 & 12 & 4 & & - & & 6 & & 3 & & - & 3 & 3 & 7 & 5 & & 3.78 \\
\hline 14 & - & - & 2 & 12 & 6 & & 1 & & 5 & & & 3.65 & - & & & 14 & 2 & & 4.06 \\
\hline 15 & 4 & 9 & 4 & 3 & - & 2. & 2 & 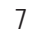 & 7 & 3 & 1 & 2.7 & 1 & 6 & 6 & 4 & 1 & 2.89 & 2.63 \\
\hline 16 & 3 & 9 & 4 & 3 & 1 & 2 & 3 & & 5 & 2 & 2 & 2 & - & 5 & 6 & 6 & 1 & 3.17 & 2.76 \\
\hline 17 & - & 6 & 6 & $\varepsilon$ & & & 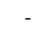 & & & & - & 2 & - & & 13 & & 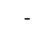 & & 3.11 \\
\hline 18 & & 5 & 12 & 3 & - & 2.9 & - & $\varepsilon$ & 8 & 4 & - & 2.8 & - & 2 & 9 & 7 & - & 3.28 & 2.99 \\
\hline 19 & - & 8 & 5 & 6 & 1 & 3 & - & 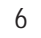 & 7 & 7 & - & 3.05 & - & - & 7 & 7 & 4 & 3.83 & 3.29 \\
\hline \multirow[t]{2}{*}{20} & 2 & 9 & 7 & 2 & - & 2.45 & 3 & 6 & 5 & 3 & 3 & 2.85 & - & 7 & 8 & 3 & - & 2.78 & 2.69 \\
\hline & & & Tota & & & 3.0225 & & & & & & 3.1075 & & & & & & 3.3635 & 3.162 \\
\hline
\end{tabular}

Comparing the results referring to the differences in teachers' perceptions of difficulties in terms of the level they taught English, figure 1 shows that teachers, teaching at different levels, have almost similar perceptions about their own and their learners' difficulties regarding English grammar instruction with a slightly higher mean for teachers of university level (3.36) comparing to those for teaches of the other levels, which are nearly the same (3.1 and 3.02)

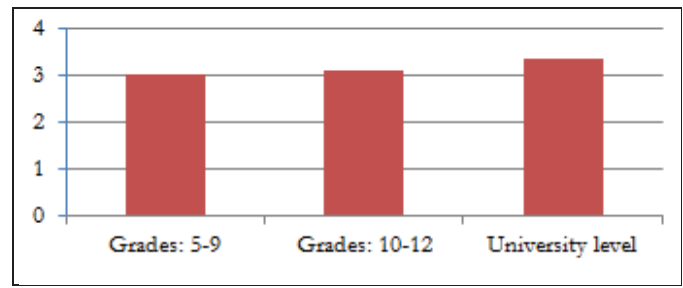

Figure 1. Teachers' perceptions of teachers' and learners' difficulties with EFL grammar according to level taught.

Explicit grammar instruction (statements 3, 4, 5, 13): As shown in table 1, the mean for teachers' perceptions on their learners' expectations to explicit grammar instruction is very high; it is rated with the highest mean (4.03) on a scale where the top value is 5. This finding is supported by the quite high mean (3.78) obtained for their perceptions on learners' feeling of insecurity in case of lack of explicit knowledge.

The results related to the teachers' perceptions on their learners' preference of learning grammar from onesentence example and finding matches between meaning and structure were lower (respectively 3.31 and 3.34); the 
teachers may have referred to learners' preference in learning some grammatical structures deductively rather than inductively and vice-versa.

Comparing the results in terms of the level taught, teachers of Grades 5-9 and university level perceive their learners to have a greater preference of explicit approach to grammar teaching and learning $(4.3,4.11)$ than those of Grades 10-12 (3.7). The use of English textbooks of Albanian authors in Grades 5-9 which often impose a deductive approach to grammar instruction and a mix-ability classroom at the university level might have influenced the higher results. The lowest and highest means of Grade 5-9 concerning their learners' preference of learning grammar from onesentence example (2.7) and finding matches between meaning and structure (3.9) showed that their learners also prefer deductive/implicit approach to grammar instruction. Surprisingly, teachers of grades 10-12 scored their learners' preference of finding matches between meaning and structure less than that of learning grammar from one-sentence example $(2.9,3.8)$.

Declarative vs. procedural knowledge (statements 1, 17, 18): What is often observed in a foreign language classroom is communication marked by low levels of linguistic accuracy, though learners have studied its grammar for many years. This is even supported by the results in this study. The mean 3.07 shows that, in the responded teachers' perceptions, their learners have difficulties in the process of transferring the knowledge about grammar (declarative knowledge) into ability to use that knowledge in real life communication (procedural knowledge). It is also supported by the results of Statements 17 and 18 (respectively 3.11, 2.99) showing that learners find it difficult to use the language accurately in both written and spoken communication.

In terms of the level taught, teachers of university level scored more than the others for having difficulties in transferring the grammatical knowledge into communicative language use and using the language accurately.

The use of grammatical terminology (statements 14, 19): The knowledge and use of grammatical terminology is considered important in EFL classroom especially by grammar-based approaches. Teaching and learning grammar (language) explicitly (deductively or inductively) often involve teachers and learners in meta-linguistic discussion: formulating the rules of grammar and syntactic analysis of phrases and sentences. Therefore it was expected similar results between learners' preference for explicit grammar instruction and the usefulness of grammatical terminology. Referring to table 1, the respective means 4.03 and 4.06 support the expectation. But while learners find grammatical terminology useful, they find less difficulty in using the terms (valued 3.29).

The difference in mean between teachers of Grades 5-9 and university level on the one hand (mean of $\geq 4$ ) and those of Grades 10-12 (mean of 3.65) seems to be higher with regard to their perceptions of the usefulness of grammatical terminology to their students; that is, teachers of the lowest and highest levels think that their students find grammatical terminology more useful than those of the middle grades. Regarding the difficulty in using the terms, teachers of university level scored higher than the others $(3.83>3.05,3.83>3)$. It may be inferred from this difference that teachers of university level attempt to assess grammatical understanding dependently of the use of terminology.

Error correction (statements 15, 16): It is suggested that errors can be tolerated in a communicative activity so as not to stop the 'flood of thought'. Statements 15 and16 produced a mean score of 2.63 and 2.76 respectively. Considering the slight difference of 0.13 between them, it may be inferred that the responding teachers experience a little bit more difficulty in correcting their learners' spoken communication than written one.

In terms of the level taught, teachers of university level scored higher than teachers of Grades 10-12 (2.89>2.7, 3.17>2.6). Teachers of Grades 5-9 scored negatively, 2.3 and 2.5 (mean of $\leq 2.5$ ), i.e. they do not seem to have difficulty correcting their learners' errors of grammar within a communicative context. This result could be related to the teachers' strategies for dealing with them. A follow-up interview with them might have provided more specific information about this issue.

Problem solving techniques (statements 2, 20): In Albanian teachers' perceptions, problems solving activities are motivating for their learners in learning grammar as they are valued 3.51. This fact is inferred by the lower mean (2.69) of statement 20 , meaning that their learners are not much frustrated by problem-solving activities.

Comparing the results in terms of the level taught, there is no significant difference between the beliefs of teachers of the three levels with regard to their learners' preference for problem-solving activities. But with regard to statement 20, there is a significant difference: the mean 2.45 (closer to the negative end than to the positive) shows that teachers of Grades 5-9 think that their learners are not frustrated by problem-solving activities. Teachers of the other levels produced a mean score of 2.85 and 2.78 respectively showing that such activities are a bit frustrating in learning grammar, possibly because of management problems as a result of a large number of learners in an English course (more than 40).

The use of authentic texts (statements $6,7,8,9,10,11,12$ ): As language is context-sensitive (an utterance is fully intelligible only in its context), grammar is best taught and practiced in context (Weaver, 1996). Though authentic texts 
show how the target structure can be used in real communication, the linguistic load of unfamiliar vocabulary and synthetic complexity can make them incomprehensible. For this reason the approach generally adopted by course book writers nowadays is: simplifying authentic texts in ways which 'retain their flavor' (Thornbury, 2008). Therefore simplified authentic texts are needed to be used.

According to the responded teachers' perceptions, students experience difficulties in learning grammar when it is presented and practiced in authentic texts: they experience more difficulties from finding form-function matches (statement 10: 3,56), vocabulary (statement 9: 3.26), variety of structures (statement 7: 3.24) than from culture boundary (statement 8: 2.75) and handling from presentation within authentic texts (statement 6: 2.92). The reason of the higher values might be the case of lack of explicitness; while that of lower values might be the use of simplified authentic texts and the integration of explicit and implicit grammar instruction.

Teachers, also, valued the use of authentic texts as they didn't find them time-consuming (rating 2.35). Surprisingly, teachers find less difficulty in producing tasks of a suitable level from authentic texts (2.6).

In comparison with teachers of Grades 5-9 and 10-12, the mean scores show that university teachers and learners find the use of authentic texts the most difficult in terms of vocabulary, variety of structures, the finding of form-function matches and producing suitable tasks. In terms of culture, university teachers scored negatively (2.34); this could be explained with the wide exposure to input that university students have during their English classes.

The use of communicative activities (statements 17, 18): Communicative activities are used in FL classes to help learners receive comprehensible input and output what is believed to lead to the development of both linguistic and communicative competence (Richards, 2002, p. 36).

The statements that refer to difficulties students might have in improving the accuracy of their grammatical language within written and spoken communicative activities are valued respectively 3.11 and 2.99. Therefore, in Albanian teachers' perceptions, their learners experience difficulties in learning grammar and improving grammatical accuracy within both writing and speaking activities (with a very slight difference between them).

In terms of the level taught, again teachers of university level scored higher (3.28) than the others $(2.8,2.9,2.95$, 3.1), but there is not a very great difference between them. The lower means may imply the teachers' concern about the lack of sufficient focus on form in communicative activities for developing grammatical knowledge.

Generally speaking, referring to the higher means scored by teachers of the university level, it might be inferred that in teachers' perceptions, both teachers and students of the university level face more difficulties regarding EFL grammar instruction. As the responded university teachers had a master's degree, it can be inferred that their response might have been influenced by their educational experience (Borg, 1998).

\section{Conclusion}

The results of this study indicated that, in teachers' perceptions, both teachers and learners faced difficulties in teaching and learning grammar, what is in line with the recent studies on this issue. Comparing the teachers' perceptions of difficulties in terms of the level they taught English, generally speaking, teachers of the university level scored higher than the others implying that both teachers and students of the university level faced more difficulties regarding EFL grammar instruction.

Considering learners' and teachers' perceptions on difficulties with regard to learning and teaching EFL grammar would help teachers decide on the right techniques for improving teaching and enhancing learning of EFL grammar to their learners. As learners and teachers of both secondary and university level face difficulty, it is advisable to include discussion on ways of coping with the difficulties in in-service and pre-service teacher training programs.

As this study is limited to two regions of Albania (Korça and Shkodra), more detailed research and analysis from other regions would enrich the data relating to difficulties of learners and teachers with regard to teaching grammar of English as a foreign language in Albania.

\section{References}

Al-Mekhlafi, A. M. \& Nagaratnam, R. P. (2011). Difficulties in Teaching and Learning Grammar in an EFL Context. International Journal of Instruction, 4(2), 69-92.

Baleghizadeh, S. \& Farshchi, S. (2010). An Exploration of Teachers' Beliefs about the Role of Grammar in Iranian High schools and Private Language Institutes. Journal of English Language Teaching and Learning, 52(212), 17-38.

Borg, S. (1998). Teachers' Pedagogical Systems and Grammar Teaching: A Qualitative Study. TESOL Quarterly, 32 (1), 9-38.

Burgess, J., \& Etherington, S. (2002). Focus on grammatical form: explicit or implicit? System, 30, 433-458. 
Celce-Murcia, M. (1991). Grammar Pedagogy in Second and Foreign Language Teaching. TESOL QUARTERLY, 25(3), 459-480.

Cohen, L. \& Manion, L. C. (1994). Research Methods in Education. London: Routledge.

DeKeyser, R. (1995). Learning Second Language Grammar Rules. Studies in Second Language Acquisition, 17, 379-410.

DeKeyser, R. \& Sokalski, K. (1996). The differential role of comprehension and production practice. Language Learning, 46, 613-642

Ellis, R. (2006). Current issues in the teaching of grammar: An SLA perspective. TESOL Quarterly, 40(1), 83-108.

Ellis, R., Loewen, Sh., Elder, C., Erlam, R., Philp, J., \& Reinders, H. (2009). Implicit and Explicit Knowledge in Second Language Learning, Testing and Teaching. Multilingual Matters.

Farrell, T.S.C., \& L. P. C. Patricia. (2005). Conceptions of Grammar Teaching: A case study of Teachers' Beliefs and Classroom Practices. Teaching English as a second language - e-Journal, 9(2).

Larsen-Freeman, D. (2000). Techniques and Principals in Language Teaching (2nd ed.). Oxford University Press.

Nassaji, H. \& Fotos S. (2011). Teaching Grammar in Second Language Classrooms: Integrating form-focused instruction in communicative context. Routledge Taylor \&Francis Group

Richards, J. C. \& Rodgers, T. S. (2001). Approaches and methods in language teaching. Cambridge Language Teaching Library.

Richards, J. C. (2002). Accuracy and Fluency Revisited. In E. Hinkel \& S. Fotos (Eds.), New perspectives on grammar teaching in second language classrooms. ESL \& Applied Linguistics Professional Series (pp. 35-50). Lawrence Erlbaum Associates, Inc.

Richards, J.C. \& Renandya, W. A. (2002) Methodology in language teaching: An anthology of current practice. Cambridge University Press.

Larsen-Freeman, D. (1991). Teaching Grammar. In Celce-Murcia, M., Teaching English as a Second or Foreign Language (pp.279283). EU: Heinle \& Heinle.

Spada, N. \& Lightbown, P. M. (2008). Form Focused Instruction: Isolated or Integrated? TESOL QUATERLY, 42(2), 181-207.

DeKeyser, R., \& Sokalski, K. (1996). The differential role of comprehension and production practice. Language Learning, 46, 613-642.

Larsen-Freeman, D. (2003). The grammar of choice. In E. Hinkel \& S. Fotos (Eds.), New perspectives on grammar teaching. Mahwah, $\mathrm{NJ}$ : Lawrence Erlbaum.

Celce-Murcia, M., \& Larsen-Freeman, D. (1999). The grammar book: An ESL/EFL teacher's course. Boston, MA: Heinle \& Heinle.

Thornbury, S. (2008). How to teach grammar. Longman.

Weaver, C. (1996). Teaching Grammar in Context. Boynton/Cook HEINEMANN

\section{Appendix}

\section{Research instrument - Questionnaire}

\section{Student and Teacher Difficulties with Grammar}

These are questions about how students and teachers deal with grammar in the classroom. Please indicate your agreement or disagreement with these statements: 5 means fully agree, 4 means agree, 3 means neither agree nor disagree, 2 disagree, 1 means strongly disagree

1. My students find it difficult to transfer their grammatical knowledge into communicative language use. 2. My students are motivated by problem-solving techniques for learning grammar.

3. My students expect teachers to present grammar points explicitly.

4. My students prefer to learn grammar from one sentence examples.

5. My students prefer to find matches between meaning and structure for themselves.

6. My students find it difficult to handle grammar presented within authentic texts.

7. My students find authentic texts difficult because of the wide variety of structures which appear.

8. My students find authentic texts difficult because they are too culture bound.

9. My students find authentic texts difficult because of the vocabulary used.

10. My students cannot find form-function matches in authentic texts without explicit direction from teachers.

\begin{tabular}{lllll}
\multicolumn{2}{c}{ Disagree } & \multicolumn{3}{c}{ Agree } \\
1 & 2 & 3 & 4 & 5 \\
1 & 2 & 3 & 4 & 5 \\
1 & 2 & 3 & 4 & 5 \\
1 & 2 & 3 & 4 & 5 \\
1 & 2 & 3 & 4 & 5 \\
1 & 2 & 3 & 4 & 5 \\
1 & 2 & 3 & 4 & 5 \\
1 & 2 & 3 & 4 & 5 \\
1 & 2 & 3 & 4 & 5 \\
1 & 2 & 3 & 4 & 5 \\
& & & &
\end{tabular}


11. Teachers find the use of authentic material too time-consuming.

12. Teachers find it difficult to produce tasks of a suitable level from authentic texts.

13. A lack of explicit grammar teaching leaves my students feeling insecure.

14. My students find grammatical terminology useful.

15. Teachers find it difficult to correct student errors of grammar within a written communicative context. 16. Teachers find it difficult to correct student errors of grammar within a spoken communicative context. 17. My students find it difficult to improve the accuracy of their grammatical language within a totally communicative writing activity.

18. My students find it difficult to improve the accuracy of their grammatical language within a totally communicative speaking activity.

19. My students find it difficult to use grammatical terminology.

20. My students are frustrated by problem-solving techniques for learning grammar.

\begin{tabular}{|c|c|c|c|c|}
\hline 1 & 2 & 3 & 4 & 5 \\
\hline 1 & 2 & 3 & 4 & 5 \\
\hline 1 & 2 & 3 & 4 & 5 \\
\hline 1 & 2 & 3 & 4 & 5 \\
\hline 1 & 2 & 3 & 4 & 5 \\
\hline 1 & 2 & 3 & 4 & 5 \\
\hline 1 & 2 & 3 & 4 & 5 \\
\hline 1 & 2 & 3 & 4 & 5 \\
\hline 1 & 2 & 3 & 4 & 5 \\
\hline 1 & 2 & 3 & 4 & 5 \\
\hline $\begin{array}{l}-12 \\
\text { Degree }\end{array}$ & $\begin{array}{l}\square U \\
\square D\end{array}$ & & & purpose) \\
\hline
\end{tabular}

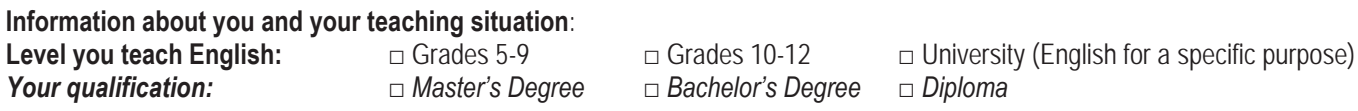

